\title{
A literatura, a liberdade e a humanização do homem
}

\author{
Thiago Henrique de Camargo Abrahão ${ }^{1}$ \\ Ulisses Infante ${ }^{2}$
}

\section{Da literatura}

A vida, a obra e o pensamento de Jean-Paul Sartre (1905-1980) inserem-se no horizonte do que Eric Hobsbawm chamou de "era dos extremos" (1995). Esse momento histórico foi marcado pelo surgimento de ideologias totalitárias, de duas guerras mundiais e da série de crises políticas, econômicas, sociais e morais que tiveram espaço ao longo do período de contrastes que foi o século xx. Tais crises - que tomaram corpo com a concepção de novos aparatos técnicos, alcançando a possibilidade do extermínio da espécie humana com o desenvolvimento da bomba atômica, malgrado a derrocada dos princípios morais - serviram de húmus para o pensamento de um escritor que pautou seus esforços na constituição de uma filosofia da liberdade apta a problematizar a existência humana, e de uma produção literária destinada a colocar o homem no centro das discussões éticas.

No que o biógrafo Bernard-Henry Lévy (200o) designou, em obra homônima, de o "século de Sartre", ${ }^{3}$ a ascensão de um pensamento humanista foi capaz de marcar os eventos na França e no mundo, contribuindo para as discussões acerca da liberdade (ou, antes, de sua falta), da posição humana diante da história (seja ela a História, seja, sobretudo, a história de cada homem), da vida humana conturbada pela perda de valores que deveriam nortear sua existência. Enquanto filósofo, Sartre propôs uma filosofia da existência que correspondesse às exigências impostas quando um abismo de sentido, e todas as consequentes contradições morais, sociais e políticas, coloca-se à frente, como um desafio a transpor a fim de assegurar linhas mestras que deem ao ser humano as balizas que o conduzam ao reconhecimento de sua condição sócio-histórica e à possibilidade de mudá-la. Enquanto romancista, pautou seus esforços para apresentar personagens em

Doutorando em teoria da literatura na da Universidade Estadual Paulista (Unesp), São José do Rio Preto, SP, Brasil. E-mail: henrique_filosofia@hotmail.com.

2 Doutor em literatura brasileira e professor da Universidade Estadual Paulista (Unesp), São José do Rio Preto, SP, Brasil. E-mail: ulissesinfante@gmail.com.

3 As traduções empregadas neste artigo são de nossa responsabilidade. 
situações extremas, em uma conjuntura que deveria permitir a discussão de uma realidade na qual o conformismo é inevitavelmente pernicioso.

A literatura sartriana, nesse contexto, reverberou os problemas sociais, culturais, econômicos, políticos, existenciais do homem. A par de conflitos como a libertação da Argélia (então colônia francesa), as guerras imperialistas na África e na Ásia e as revoluções socialistas, escritores e filósofos como Sartre e Albert Camus, aliando a produção literária aos ditames de suas filosofias, fizeram de seus escritos obras ligadas a causas a defender. Pautaram-se, para isso, na defesa de ideais os mais urgentes em uma época em crise, em que seria necessário um pensamento crítico que afrontasse o colapso de valores até então tidos como eternos (ou assim se queria) e as contradições então reinantes, seja nas ideias, seja nas ações dos homens.

A necessidade de pensar a história - e na história - levou, portanto, Sartre e outros pensadores a conceberem novos significados para o passado, a considerarem os desafios do presente e a imaginar outros e melhores rumos para a humanidade. Ora, pensar a literatura nesse meio exigia tratá-la enquanto questão social, não alienada da existência e dos problemas humanos, pois o fazer literário seria capaz, por meio da linguagem, de mostrar, discutir e, no melhor dos casos, contribuir para a transformação de determinadas circunstâncias socialmente negativas. Ao encontro dessa perspectiva, esclarece-nos Antonio Candido (2010, p. 79) que

as manifestações artísticas são inerentes à própria vida social, não havendo sociedade que não as manifeste como elemento necessário à sua sobrevivência, pois [...] elas são uma das formas de atuação sobre o mundo e de equilíbrio coletivo e individual. São, portanto, socialmente necessárias, traduzindo impulsos e necessidades de expressão, de comunicação e de integração que não é possível reduzir a impulsos marginais de natureza biológica.

Tais "impulsos e necessidades de expressão", para Sartre, diziam respeito à responsabilidade dos escritores de agirem, visto que as pressões morais da época apontavam para a necessidade imperativa de os intelectuais repensarem a relação do ser humano com sua própria realidade, a partir de uma tomada de consciência historicizante do que é existir e, por conseguinte, também a relação do cidadão com a sociedade. Assume-se, pois, que as questões sociopolíticas de uma época dizem respeito a todos que a vivenciam. Desse modo, Sartre entendeu ser necessário engajar a literatura, estabelecendo-a em um mundo no qual o mutismo, o quietismo, a passividade, a conivência (ou outra palavra que 
expresse apatia intelectual diante da antipatia do mundo) tornaram-se particularmente nocivos no contexto europeu do século $\mathrm{xx}$, como provam os campos de concentração nazistas e os gulags soviéticos, posto que enfraqueciam a liberdade de pensamento e, a fortiori, a autonomia do homem em meio a políticas de exceção que poderiam ser (e foram) enredos de história distópicas.

Destaque-se que a produção crítica de Antonio Candido também surge durante a "era dos extremos", vivenciada num contexto periférico em relação ao do filósofo francês. Candido atravessou dois períodos ditatoriais brasileiros, durante os quais manteve militância política e intelectual. Seu desempenho como professor universitário nunca deixou de incorporar uma vigilante lucidez em relação ao próprio papel social. Em um encontro de intelectuais realizado em Havana, em 1985, Candido assim apresentava o quadro da falta de democratização do acesso ao conhecimento no Brasil:

É inegável que o Brasil possui uma elite intelectual de alta qualidade e muitas instituições de ensino cujo padrão é de franca excelência. Por isso, a sua produção científica, literária, artística é intensa e valiosa. Mas o ensino superior é fraco e restrito de modo geral, o médio padece de uma mediocridade tradicional e o primário nunca atingiu a finalidade mínima de dar instrução a todos. Ao modo dos ilustrados do passado, o brasileiro continua orientando-se pela ideia da importância privilegiada dos níveis superiores, segundo os quais se define o homem que sabe e por isso manda sem se preocupar, no fundo, com a difusão do conhecimento para todos. Isto é: sem querer retirar da esfera da utopia a ideologia redentora da Ilustração (CANDIDO, 2002, p. 326).

Esse discernimento crítico em relação ao próprio papel como intelectual recobre coerentemente a prática de crítica literária de Antonio Candido e das relações que a atividade crítica mantém com a sociedade em que circula. A ninguém que vivencia o próprio momento histórico lucidamente se pode conceder o privilégio de abster-se da ação social - e aos que detêm saberes essa abstenção seria ainda mais recriminável: a adoção dessa deliberada ética da prática literária aproxima Candido e Sartre.

Quanto ao homem, individualmente, compreendido como liberdade a se fazer na história (e, com isso, a fazer a história) enquanto é feito por ela, Sartre insiste na concepção de uma moral, mas não de um processo moralizante, que se insere entre as estruturas sociais e a práxis individual. O engajamento literário, então, vai ao encontro de tais ideias, posto ser a escrita uma forma de ação. Diante do contexto histórico em que se encontrava Sartre, para este 
Thiago Henrique de Camargo Abrahão

ULISSES INFANTE

o escritor não deveria prever ou conjecturar passivamente, mas se comprometer e projetar novas perspectivas. O filósofo e escritor francês defenderá, pois, uma literatura ativa, pautada na liberdade responsável das partes envolvidas: por não existir sozinho, por não escrever apenas para si, o escritor teria, pois, de considerar a contraparte de seus esforços de criação, a saber, seu interlocutor. Por conseguinte, a literatura passou a ser entendida como um esforço mútuo, de imaginação e de compreensão, entre duas consciências que se exigem, a do escritor e a do leitor, ambos atentos, idealmente, a respeito do mundo em que vivem.

Esse nexo de solidariedade entre escritor e leitor especularmente concebidos não é de maneira alguma estranho às concepções de Antonio Candido, para quem o processo comunicativo que se institui é "integrador e bitransitivo" (CANDIDO, 2010, p. 32), o que faz crer que o "efeito" mencionado a seguir pode ser pensado como sintonia entre consciências que se procuram:

Como se vê, não convém separar a repercussão da obra da sua feitura, pois, sociologicamente ao menos, ela só está acabada no momento em que repercute e atua, porque, sociologicamente, a arte é um sistema simbólico de comunicação inter-humana, e como tal interessa ao sociólogo. Ora, todo processo de comunicação pressupõe um comunicante, no caso o artista; um comunicado, ou seja, a obra; um comunicando, que é o público a que se dirige; graças a isso definese o quarto elemento do processo, isto é, o seu efeito (CANDIDO, 2010, p. 32).

Ao projetar um compromisso do escritor para com sua sociedade, Sartre viu na literatura uma forma de capacitar os homens a construírem a mediação necessária entre escritor e leitor para ser possível a tomada de consciência de uma situação conformista cuja aceitação passiva dos homens a faz permanecer perigosamente inalterada. A leitura, então, assenta-se em um movimento de generosidade, pois leitor e autor devem ser depositários de confiança um no outro, sendo um processo não obrigatório a acarretar uma escolha independente de ambos e a estabelecer um processo dialético em que ambas as partes se exigem, se afetam e fomentam o desvendamento da liberdade um do outro. Em face da dificuldade ou impossibilidade humana em escapar dos condicionamentos sociais impostos, a literatura poderia ser um meio pelo qual o escritor, a partir de sua liberdade (desde que assegurada), pudesse apelar à liberdade do leitor para fazê-lo consciente de sua (do leitor) situação, possibilitando-lhe compreendê-la, agir a respeito, modificá-la. Sartre opõe, portanto, contemplação desinteressada e compreensão crítica, esta a incitar 
o fazer literário a ser instrumento de conscientização, não de puro entretenimento ou fruição - daí que a ideia kantiana de "prazer sem interesse" (KANT, 1995, p. 68) é negada em favor de um compromisso social acompanhado de uma responsabilidade histórica (SARTRE, 1948, p. 98).

Em outras palavras, a literatura não existe para simples distração, pois, antes de entreter, tem sua importância pautada na compreensão da maneira de agir do homem, de modo que fazer do texto literário simples entretenimento é, segundo Sartre, ignorar o poder inerente a ele. Ao escritor caberia a responsabilidade de elucidar o obscurecido a partir da identificação crítica da alienação que sujeita o homem, contribuindo com possíveis mudanças a partir da ação (o segundo passo) que se segue ao (primeiro passo que é o) reconhecimento e à compreensão da realidade. Sendo o livro um "se" cujo "então" exige a participação do leitor, comunicar-se literariamente exige o retorno à contraparte da escrita, exige a necessidade de fazer com que seja considerada, pelo leitor, a possibilidade de ir além da coisa escrita estabelecida pelo autor. Desse modo, a literatura seria capaz de promover uma perspectiva mais ampla da realidade, sem excluir o ângulo dialético que permite aos leitores perceberem a existência em suas nuanças e em seus limites, função esta importante porque, de acordo com Candido, a literatura

tem sido um instrumento poderoso de instrução e educação, entrando nos currículos, sendo proposta a cada um como equipamento intelectual e afetivo. Os valores que a sociedade preconiza, ou os que considera prejudiciais, estão presentes nas diversas manifestações da ficção, da poesia e da ação dramática. A literatura confirma e nega, propõe e denuncia, apoia e combate, fornecendo a possibilidade de vivermos dialeticamente os problemas (CANDIDO, 1995, p. 175).

Relacionado à liberdade, à linguagem e à ação, outro importante conceito no pensamento sartriano, a saber, o engajamento, tenciona afirmar a responsabilidade dos escritores para com o esclarecimento do mundo - por meio da linguagem, do trabalho no plano formal - e o consequente ímpeto em mudá-lo. A literatura engajada, nesse sentido, aproxima-se do que Candido chamou de "literatura empenhada", uma literatura "que parte de posições éticas, políticas, religiosas ou simplesmente humanísticas. São casos em que o autor tem convicções e deseja exprimi-las; ou parte de certa visão da realidade e a manifesta com tonalidade crítica" (CANDIDO, 1995, p. 180-181). Nesse sentido, por sua natureza não crítica, mas conivente com a realidade, a literatura de diversão não consideraria a possibilidade de mudança sociopolítica, pois, pelo 
Thiago Henrique de Camargo Abrahão

ULISSES INFANTE

contrário, teria o objetivo de manter o status quo - o que, para a época de Sartre, seria impensável para o intelectual que tencionasse fazer alguma diferença em prol do resgate do que há (ou pode haver) de humano no ser sócio-histórico.

\section{Da liberdade}

A filosofia da existência, outro nome dado ao movimento existencialista francês, que teve em Sartre o seu mais importante porta-voz, funda-se na tentativa de dar respostas às inquietações ontológicas do homem, pois se debruça na compreensão da existência humana e na defesa dos aspectos essenciais de sua constituição. O pensamento existencialista abordou importantes problemas do século xx, entre os quais as questões morais e as contradições humanas, sublinhadas pela sensação de náusea surgida da responsabilidade humana, que advém àqueles que não mais admitem nenhum guia senão eles mesmos no exercício dessa responsabilidade. Disso se segue o existencialismo ateu de Sartre, o qual, diríamos, revisitando o inquisidor de Dostoiévski em Os irmãos Karamazov, poderia assumir, sem embargo, que "Se Deus não existe, tudo é responsabilidade".

Essa corrente filosófica, cuja palavra-chave é a liberdade e tem em L'être et le néant (SARTRE, 1943) sua obra principal, parte de um princípio fundamental, a saber, que a existência humana precede sua essência. Isso significa que o homem não possui uma essência a priori (o que exclui a necessidade de um deus que a conceba), mas, sim, ele primeiro surge no mundo para depois, e continuamente, se definir, se fazer aquilo que é e será. Com a primazia da existência sobre a essência, o homem é liberdade, mas não uma liberdade abstrata, alienada das condições sociais e históricas. A liberdade não é, tampouco, uma faculdade humana, uma disposição para agir (como quando dizemos que somos livres para abrir ou fechar um livro), pois não se trata de algo que o homem tem, mas algo que o homem é. Trata-se do fundamento ontológico do homem porque, segundo o filósofo, "o homem é, primeiramente, um projeto que se vive subjetivamente, em lugar de ser uma massa, um bolor, uma couve-flor" (SARTRE, 1958, p. 23). A liberdade é entendida pelo pensador francês como capaz de alterar a racionalidade ocidental, presa a valores ultrapassados e a máximas deterministas que proíbem o homem de ser senhor de sua própria história: assim, há uma recusa em crer em um determinismo que coíbe o ser humano de suas próprias iniciativas e responsabilidades. 
A liberdade acarreta ao homem um perene exercício de constituição e de significação de si mesmo, exercício que se situa em um horizonte de possibilidades que já existiam quando ele surgiu (sua condição social, seu ambiente histórico etc.) e que ele pode aceitar ou recusar. Esse todo, a facticidade da existência, constitui, para o sujeito humano, uma dada situação, diante da qual a sua ação significa, pois, uma reação às condições que permeiam o exercício de sua liberdade. Portanto, a liberdade para o existencialismo diz respeito ao livre confronto com as adversidades, conflito que somos condenados a aceitar, com o fito de superá-las para a realização de nosso projeto livre de ser - um projeto livre que pressupõe um ser livre. Desse modo, a filosofia da existência leva o homem a assumir aquilo que é, bem como as consequências que disso se seguem, pois toda escolha livremente tomada acarreta uma responsabilidade - que não se encerra na individualidade, haja vista essa responsabilidade dizer respeito a todos os homens, a todas as consciências de um mesmo presente.

Disso se segue que a concepção da liberdade é, para Sartre, uma ideia que orienta um projeto ético pautado na reflexão sobre as possibilidades, em um contexto histórico-social contingente, de uma práxis da liberdade, pois o fato de nascermos em dado contexto compromete-nos com ele. Entre as possibilidades, a indiferença e a dissimulação são opções que podem ser eleitas diante dos problemas de nosso tempo. Nesse caso, ao fugirmos de nossa responsabilidade, mentindo a nós mesmos sobre o que somos e sobre o compromisso que devemos assumir, estaremos diante do que Sartre chamou de "má-fé" - que não é idêntica à mentira, pois esta pressupõe que o enganador e o enganado são indivíduos distintos - , a supor, esta, uma dissimulação que o homem faz a si mesmo para esconder de si sua liberdade e sua responsabilidade.

Ao viver sua condição histórica, o homem se descobre entre sua condição existencial livre, sem essência predeterminada e a demandar sua própria constituição, bem como sua condição ética, posto que vive com outras consciências que, como ele, também são livres para agirem e elegerem seus valores. Uma vez que não traz em si determinação alguma, o homem, ser dos possíveis, é abertura a todas as possibilidades: sem predeterminações ontológicas, é obrigado a voltar-se para o mundo e para os homens para se completar. O ser humano, por esse viés, é sua capacidade de se inventar, é disposição permanente para escolher o que quer chegar a ser. Em suma, 
o imperativo da liberdade humana complementa-se com a responsabilidade reivindicada por essa liberdade.

Antonio Candido expressa ponto de vista afim quando, em texto publicado inicialmente no jornal $O$ Estado de S. Paulo em 15 de julho de 1943, como resposta a uma enquete promovida por Mário Neme, destaca a necessidade da ação transformadora socialmente responsável em lugar de "discussões metafísicas" que propõem "ao homem soluções de elite, normas 'to the happy few', ou a consecução de alvos extraterrenos, passando, de uma forma ou de outra, por sobre os problemas da sua existência atual" (CANDIDO, 2002, p. 246):

Ora, não se pode negar um grande valor a tal filosofia. Sobretudo porque, de uma maneira ou de outra, coloca problemas de ordem dramática e leva a extraordinárias aventuras espirituais. Como lhe disse, todavia, não se trata aqui propriamente de reconhecer ou negar valores em si, mas de perguntar até que ponto, nos tempos que correm, esses valores podem servir, não ao problema agonístico "do Homem", mas à condição, à situação imediata 'dos homens'. Este é que têm realidade e são a instância definitiva. Julgada segundo a eficiência que apresenta quanto à felicidade deles é que podemos aquilatar o grau de resistência de uma ideia. A resolução das contradições sociais que prolongam a injustiça na terra é a pedra de toque para se julgar da dignidade humana de um sistema (CANDIDO, 2002, p. 246).

Responsáveis que somos, sem ninguém para culpar senão nós mesmos caso nosso projeto de ser não se realize - ou mesmo se se realizar, pois há responsabilidade também aí -, a isso Sartre dá o nome de "compromisso" ou, a seu modo, "engajamento" (SArTre, 1948, p. 76). Presente em cada escolha, ato, palavra ou silêncio, é pelo engajamento - a não dizer respeito apenas a uma ação de cunho político - que o homem é capaz de afirmar seus valores morais, de tomar consciência de si e de assumir sua realidade. Enquanto consciência, não há, para o ser humano, qualquer possibilidade de ação que não esteja inserida no mundo, que não se dê em uma situação específica, de modo que o mundo é revelado pela consciência humana como um contexto pleno de atos a realizar. Ora, por não ser o homem mero espectador a contemplar um mundo envolto em questões e problemas que, assim se pensa (ou assim se quer, por má-fé, pensar), não lhe dizem respeito, sua existência é pautada, na verdade, por seu engajamento quanto às questões que a concretude histórica propõe e às quais dele exige respostas. 
Vemos, por isso, que as personagens dos romances sartrianos encontram-se divididas entre a má-fé e a autenticidade - ou seja, entre a possibilidade de iludir-se com desculpas que as salvaguardem da responsabilidade inerente às suas escolhas e a admissão da facticidade da existência a partir da aceitação da responsabilidade pela situação humana. Isso traz ao leitor a problematização de sua própria existência, também cindida entre a autenticidade e a má-fé, possibilitando o confronto com as questões básicas que nos formam enquanto seres em situação, admitindo, por isso, a reflexão, a autorreflexão, a consciência de coletividade etc. Nesse jogo existencial, o papel da literatura, segundo Sartre, aproxima-se do papel que tem a literatura para Candido no que concerne ao seu processo de humanização, que, segundo o estudioso brasileiro:

confirma no homem aqueles traços que reputamos essenciais, como o exercício da reflexão, a aquisição do saber, a boa disposição para com o próximo, o afinamento das emoções, a capacidade de penetrar nos problemas da vida, o senso da beleza, a percepção da complexidade do mundo e dos seres, o cultivo do humor (CANDIDO, 1995, p. 180).

Diante do presente em que o homem se encontra, mistura de problemas metafísicos (em relação à necessária e livre constituição de sua essência) e de problemas históricos (envoltos pela situação com a qual os homens se deparam na manifestação de sua liberdade), as questões que são propriamente nossas são aquelas que nosso próprio tempo nos coloca. Ao lado da reflexão filosófica, a literatura, então, enquanto possibilidade de construção de experiências fictícias, oferece-se como um caminho de elucidação do homem e de seus problemas, pois filosofia e literatura são, mutatis mutandis, possibilidades de compreensão da consciência engajada em seu presente.

Observe-se que o conjunto de traços que Candido considera "essenciais" permite aproximar o que ele chama de confirmação da humanidade do ser humano do "engajamento" sartriano. Afinal, refletir, adquirir saber, abrir-se ao próximo e à diferença, aprimorar as emoções e a capacidade de analisar os problemas do cotidiano pessoal e social, educar-se esteticamente e também para a riqueza da diversidade do mundo são passos do percurso de consolidação da própria autonomia existencial necessária ao exercício ético da liberdade humana. Como uma forma de exercício perene de autocrítica nesse percurso, o "cultivo do humor" parece surgir no final da relação de traços essenciais: o humor prevê o viés inusitado, a autoironia, a percepção da omissão ou do equívoco na conduta e a readequação desta ao projeto pessoal 
de autonomia intimamente vinculado às práticas sociais responsáveis. A literatura humaniza porque integra o projeto pessoal de lucidez e solidariedade.

Ao fazer da literatura parte de seu instrumental de pensamento e ação, Sartre voltou-se para a organização de um corpo teórico e estético que pautasse seu fazer literário. Combinando "sofisticação intelectual com uma sensibilidade propriamente estética” (JAMESON, 1997, p. 23), além de uma orientação humanista, surge do trabalho literário de Sartre um pensamento geral, de caráter marxista, sobre a capacidade de influência das criações artísticas no mundo, sempre pautadas no decurso da historicidade em que se encontram o artista e seus leitores. A lidar tanto com a particularidade das situações como com o absoluto que é o homem, temos que a literatura sartriana encontra-se nesse cruzamento contraditório, a aliar ética e estética, universal e particular, metafísica e história, literatura que, enquanto construção operada pelo escritor,

está ligada à complexidade da sua natureza, que explica inclusive o papel contraditório, mas humanizador (talvez humanizador porque contraditório). Analisando-a, podemos distinguir pelo menos três faces: (1) ela é uma construção de objetos autônomos como estrutura e significado; (2) ela é uma forma de expressão, isto é, manifesta emoções e a visão do mundo dos indivíduos e dos grupos; (3) ela é uma forma de conhecimento, inclusive como incorporação difusa e inconsciente (CANDIDO, 1995, p. 176).

Essa literatura, enquanto questionamento sobre a ordem humana, enquanto forma de conhecimento humanizante, se dá, segundo Sartre, por meio de uma passagem entre o mundo do imaginário, irreal, próprio das manifestações artísticas, e a existência histórica ou o mundo real. Sendo o homem o ser para o qual seu próprio ser está em questão e constantemente a ser feito, escolhido, significado por si e pelos outros, some-se a isso que, diante da necessidade de conceber incessantemente a sua própria essência, por não ser possível chegar a uma resposta definitiva sobre si, há também o problema de ser impossível uma elaboração definitiva da pergunta quanto à sua existência. Isso se dá porque não há, por um lado, essência preconcebida que sirva como alicerce para seus questionamentos e, por outro lado, a própria historicidade flui sem deixar que o homem se ancore em algo que lhe dê certezas inabaláveis. Daí porque a literatura engajada requisita à imaginação que sorva a realidade, junto a recuperação de uma totalidade, de uma historicidade, de uma liberdade, de 
uma responsabilidade, dissimuladas ou coagidas por poderes que não dizem respeito à humanidade. Por esse viés, e segundo Candido,

a literatura satisfaz, em outro nível, à necessidade de conhecer os sentimentos e a sociedade, ajudando-nos a tomar posição em face deles. É aí que se situa a literatura social, na qual pensamos quase exclusivamente quando se trata de uma realidade tão política e humanitária quanto a dos direitos humanos, que partem de uma análise do universo social e procuram retificar as suas iniquidades (CANDIDO, 1995, p. 180).

É o fato de ser livre, portanto, que lança o homem na elaboração constante de perguntas e de respostas sobre si e sobre o mundo, e, em face disso, a literatura admite a possibilidade de humanizar a partir da elucidação do compromisso, da responsabilidade, da historicidade que se evidencia no momento da leitura. Autor e leitor são depositários de suas liberdades e, juntos, fazem surgir a obra que, em seu escopo, apresenta o desvelamento das consciências em jogo e do mundo real que é espelhado no universo do irreal ideia que confirma o pensamento de Candido, quando este afirma que "A literatura desenvolve em nós a quota de humanidade na medida em que nos torna mais compreensivos e abertos para a natureza, a sociedade, o semelhante" (CANDIDO, 1995, p. 180). Disso se segue que não pode haver espaço para a neutralidade diante das questões apresentadas nos textos literários do autor. A estabelecer o que Candido (2010, p. 135) chamou de "o conflito entre a inteligência participante $\mathrm{e}$ a inteligência contemplativa”, ecoam, em cada história, em cada personagem, questionamentos morais. Tais questionamentos demandam, dos leitores, não a contemplação desinteressada da manifestação artística, mas a atenção crítica ao engajamento que se estabelece quando são lidas e exploradas as histórias que, ao preço de nos fornecer uma consciência infeliz, exigem-nos uma participação quanto à compreensão do mundo narrado - este, a recuperar o mundo real que contém os problemas que não são alheios a nós mesmos.

Ao fazer convergir para os mesmos propósitos os recursos conjugados da filosofia e da literatura, e diante da falta de discussões mais amplas, que não fiquem apenas dentro das reuniões diplomáticas e/ou dos muros de marfim da Academia, Sartre tentou evidenciar as limitações e as possibilidades de indivíduos concretos, homens situados na história, entranhados no cotidiano, por vezes desconfortavelmente lúcidos. A importância da literatura se coloca, pois, em sua capacidade de descrever a realidade humana tal qual é vivenciada 
por personagens, indivíduos, seres em situação, isto é, de tratar de temas e contextos no seio das atitudes humanas, já que a filosofia, por seu tratamento teórico-conceitual, não é capaz de descrever a realidade humana dos indivíduos e suas particularidades contextualizadas, cujos parâmetros e variáveis dificilmente são captados pela linguagem filosófica. Ainda que possa (e mesmo deva, como quer o marxismo) aproximar-se da concretude histórica, a filosofia depende do tratamento do universal, e é por essa contradição que é assegurado o valor de ambos os modos de expressão, seja a literatura, seja a filosofia, cada um a complementar, de acordo com uma perspectiva diferente e de maneiras distintas, a realidade humana.

Em resumo, para Sartre, a filosofia é capaz de descrever conceitualmente o homem, mas com isso perde a capacidade de retratar o que o homem é e faz (papel próprio da literatura). A literatura, por sua vez, apesar de não trabalhar do mesmo modo com conceitualizações, é capaz de retratar o homem em seu contexto, e a experiência histórica (que na realidade é apresentada em fragmentos), de maneira totalizadora: "é uma verdade que se torna, que se organiza minuciosamente, é toda uma existência humana que passa do abstrato ao concreto, da miséria à riqueza, do universal ao singular, da objetividade anônima à subjetividade" (SARTRE, 1964, p. 44). Como nem a filosofia nem a literatura são capazes de conceitualizar e de retratar ao mesmo tempo, a comunicação frutífera entre elas permite que Sartre trabalhe uma temática como a da contingência da existência humana, no caso do romance La nausée (SARTRE, 1938), ou a liberdade, em La mort dans l'âme (SARTRE, 1949) - a partir de duas perspectivas, havendo uma complementação de discursos a partir da qual o que a filosofia é incapaz de explicitar a literatura o faz, e vice-versa. A distinção primordial entre os dois gêneros está, para Sartre (1976, p. 137), ligada à questão da univocidade, evidenciando-se, com isso, o problema do controle do sentido, que, se por um lado é exigência do discurso filosófico, por outro lado deixa, sob certo ângulo, de ser problema para a literatura: a ambiguidade do literário, aberto a múltiplas interpretações, prescinde do controle do sentido pelo escritor.

\section{Da humanização}

Algo existe, hoje, no cerne da realidade, capaz de fazer com que seja natural fantasiá-la com esquecimentos e distorções. No homem, vemos um semblante 
igualmente adornado - mas com sucessivas máscaras. Para despi-la e nos despir devemos nos lembrar de que a inteligência, filha da insatisfação, nunca admitiu, quando praticada, a proibição do direito ao senso crítico, ao livrepensar. Exterior a nós, o não peremptório não se nota: um véu lançado à frente condenou as perspectivas, dificultando nossa compreensão do mundo. Para retirá-lo de nossas cabeças, haveria, para Sartre, a literatura - mas não apenas, como o escritor posteriormente aceitou. ${ }^{4}$ É diante da perda da liberdade da arte, devido à sua submissão aos imperativos do gosto terceirizado, que hoje, tanto quanto na época do escritor francês, faz-se essencial problematizar com mais profundidade o mundo e também os motivos pelos quais a literatura, inevitável veículo ideológico, torna-se ela mesma um problema - contraditoriamente, por sua conivência com os problemas. A esse respeito, e fazendo coro a Candido, "uma sociedade justa pressupõe o respeito dos direitos humanos, e a fruição da arte e da literatura em todas as modalidades e em todos os níveis é um direito inalienável" (CANDIDO, 1995, p. 191).

De acordo com o que acompanhamos, a obra literária sartriana, ainda que por vezes ingênua e redutora, pautou-se em tentar ser um reflexo (e uma reflexão) da consciência do ser humano. Sartre, pensando o indivíduo enquanto parte da coletividade, e a coletividade enquanto parte da história, esforçou-se para escrever a fim de dar a pensar - mesmo porque quem não pensa é pensado -, a fim de afirmar que a liberdade humana não é uma abstração inerte, mas o ingrediente mais íntimo do que é o ser humano; livre, sim, mas também responsável, comprometido com o que escolhe e com o que deixa de escolher, com o que pensa e diz, bem como com o que ignora ou silencia. Isso leva à reflexão sobre nosso próprio modo de considerar a literatura em nossa época, como a empregaremos em nosso próprio momento histórico, em nossos próprios problemas, os quais, queiramos ou não, são refletidos em e por nossas práticas.

Candido (1995, p. 186), por sua vez, considera que "a literatura corresponde a uma necessidade universal que deve ser satisfeita sob pena de mutilar a personalidade, porque pelo fato de dar forma aos sentimentos e à visão do mundo ela nos organiza, liberta-nos do caos e, portanto, nos humaniza”. Essa afirmação nos permite vislumbrar uma aproximação com o pensamento

4 É válido ressaltar que não queremos afirmar, aqui, que a arte, por si só, é capaz de resolver os problemas do mundo, ou simplesmente de ordená-los e significá-los. Mas, embora não seja condição suficiente, a literatura é condição necessária para tanto, pois por ela passam valores, juízos, possibilidades, receios, orgulhos, nojos, esperanças, em suma, tudo o que faz parte de uma formação lúcida do homem, como salientou Candido (2002). 
sartriano, pois ambos, em sua época e a seu modo, afirmaram e defenderam o papel fundamental da literatura, em sua concepção e em sua leitura, na concepção da vida humana individual e social, posto que "negar a fruição da literatura é mutilar a nossa humanidade" (CANDIDO, 1995, p. 186). Sejam quais forem os caminhos a seguir, podemos ao menos aceitar que as questões são muitas e as respostas nunca serão definitivas. Mas, antes de ser um problema, a impossibilidade de conclusões categóricas ocasiona um processo produtivo resultante da constante e inevitável significação das questões e das respostas que se colocam à frente do homem - dinâmica que se coaduna com o constante processo de retomada e significação que é, segundo Sartre, a existência de cada indivíduo no mundo.

\section{Referências}

Candido, Antonio. Literatura e sociedade. Rio de Janeiro: Ouro sobre Azul, 2010.

CAndido, Antonio. Textos de intervenção. São Paulo: Duas Cidades, 2002.

Candido, Antonio. Vários escritos. Rio de Janeiro Ouro sobre Azul, 1995.

HobSBAwm, Eric. Era dos extremos: o breve século xx. 2. ed. Tradução de Marcos Santarrita. São Paulo: Companhia das Letras, 1995.

Jameson, Fredric. O marxismo tardio: Adorno, ou a persistência da dialética. Tradução de Luiz Paulo Rouanet. São Paulo: Boitempo, 1997.

Kant, Immanuel. Crítica da faculdade do juízo. 2. ed. Tradução de Valerio Rohden e António Marques. Rio de Janeiro: Forense Universitária, 1995.

Levy, Bernard-Henri. Le siècle de Sartre: enquête philosophique. Paris: Bernard Grasset, 2000.

SARTre, Jean-Paul. La nausée. Paris, Gallimard, 1938.

SARTre, Jean-Paul. L'être et le néant. Paris: Gallimard, 1943.

SARTre, Jean-Paul. Situations, II. Paris: Gallimard, 1948.

SARTre, Jean-Paul. La mort dans l'âme. 89. ed. Paris: Gallimard, 1949.

SArtre, Jean-Paul. L'existentialisme est un humanisme. Paris: Éditions Nagel, 1958.

SARTre, Jean-Paul. Situations, IV. Paris: Gallimard, 1964.

SARTRE, Jean-Paul. Situations, x. Paris: Gallimard, 1976.

Recebido em 19 de fevereiro de 2017.

Aprovado em 5 de abril de 2017. 


\section{Resumo/Abstract/Resumen}

\section{A literatura, a liberdade e a humanização do homem}

Thiago Henrique de Camargo Abrahão

Ulisses Infante

Em virtude da diminuição paulatina do senso histórico dos homens - consciências por isso passíveis, diante da realidade social, a viverem em meio a valores fragmentados que não permitem uma compreensão mais completa e profunda de sua situação no mundo haveria, segundo Jean-Paul Sartre, uma função para a literatura, a saber, ser um meio para estimular a percepção da liberdade e da responsabilidade do homem, evidenciando, com isso, o papel humanizador da arte literária, fundada sobre o alicerce de um pensamento filosófico (o existencialismo) que se quer um humanismo. A partir do pensamento sartriano, veremos que as ideias do crítico literário brasileiro Antonio Candido sobre o papel da literatura convergem para os mesmos propósitos, de modo que, de nossa parte, sublinharemos a importância das afirmações teóricas dos dois estudiosos para debatermos a atualidade.

Palavras-chave: literatura, humanismo, liberdade, responsabilidade, Jean-Paul Sartre, Antonio Candido.

\section{Literature, freedom and the humanization of man}

Thiago Henrique de Camargo Abrahão

Ulisses Infante

Because of the gradual decrease in the historical sense of men - consciences, therefore, susceptible to the social reality, living amid fragmented values that do not allow a more complete and thorough understanding of their situation in the world there would be, according to Jean-Paul Sartre, a function for literature, namely, to be a means to stimulate the perception of freedom and man's responsibility, demonstrating thereby the humanizing role of literary art, founded in the basis of a philosophical thought (the existentialism) which wants to be a humanism. From the Sartrean thought, we see that the Brazilian literary critic Antonio Candido's ideas on the role of literature converge for the same purposes, so that, on our part, we will underline the importance of the theoretical statements of the two thinkers to debate the present.

Keywords: literature, humanism, freedom, responsibility, Jean-Paul Sartre, Antonio Candido. 
Thiago Henrigue de Camargo Abrahão

ULISSES INFANTE

\section{Literatura, libertad y la humanización del hombre}

Thiago Henrique de Camargo Abrahão

Ulisses Infante

Debido a la disminución gradual del sentido histórico de los hombres - consciencias, por tanto, pasivas frente a la realidad social, viviendo en medio de valores fragmentados que no permiten una comprensión más completa y profunda de su situación en el mundo habría, para Jean-Paul Sartre, una función para la literatura, a saber: ser un medio para estimular la percepción de la libertad y de la responsabilidad del hombre, demostrando así el papel humanizador del arte literario, fundado en un pensamiento filosófico (el existencialismo) que quiere ser un humanismo. Desde el pensamiento sartreano vemos que las ideas del crítico literario brasileño Antonio Candido sobre el papel de la literatura convergen hacia los mismos propósitos, de manera que, por nuestra parte, subrayaremos la importancia de las declaraciones teóricas de los dos pensadores para debatir el presente.

Palabras clave: literatura, humanismo, libertad, responsabilidad, Jean-Paul Sartre, Antonio Candido. 